\title{
LA REVANCHA POLÍTICA DE LAS EMOCIONES: ¿AMENAZA FANTASMA?
}

José Andrés Fernández Leost

Universidad Complutense de Madrid ${ }^{1}$

http://dx.doi.org/10.5209/NOMA.54910

Resumen.- El rebrote de movimientos populistas y nacionalistas ha situado en primer plano la cuestión de la ascendencia de las pasiones en la política. Al mismo tiempo, la neuro-ciencia está replanteando los presupuestos que explican la actividad fisiológica y cerebral humana, incorporando el componente emocional. El libro La democracia sentimental del profesor Manuel Arias Maldonado, cubre los progresos de la teoría política, actúalizando y reubicando la disciplina a la altura de los tiempos, marcados por el "giro afectivo". De este modo, el autor realiza un profundo estudio, enfocado a preservar la tesis de la autonomía individual (a re-soberanizar al sujeto post-soberano), en virtud de nuevas bases: aquellas que proporciona el conocimiento sobre los límites de nuestra racionalidad. Asimismo, perfila una propuesta normativa que renueva el atráctivo del "liberalismo político" ante el ímpetu político de las emociones, en una obra que invita a profundizar en múltiples líneas de investigación.

Palabras clave: giro afectivo, democracia, emociones, neurociencia, liberalismo

Abstract.- The resurgence of populist and nationalist movements reveals the importance of passions in politics. At the same time, the scientific advances of neurology are rethinking the premises that explain brain activity, incorporating the role of emotions. In his work, Sentimental Democracy, Professor Manuel Arias Maldonado reflects the progress of Political Theory, framing the discipline in the academic context of "the affective turn". In this way, the author presents a study focused on the preservation of individual autonomy (to re-sovereignize the post-sovereign subject), according to new assumptions: those that provide knowledge about the limits of our rationality. It also outlines a normative proposal that renews the contents of "political liberalism" in a book that covers diverse lines of research.

Key words: affective turn, democracy, emotions, neuroscience, liberalism

"La política no es geometría". Con este enunciado arrancaba el profesor Benigno Pendás su libro Teorías políticas para el siglo XXI (2007). Se trataba de resaltar el estatuto epistemológicamente frágil que guarda la disciplina, además de advertir contra todo ejercicio desproporcionado de ingeniería social, en favor de un prudente moderantismo. O de matizar el estricto racionalismo científico-político con la introducción de una razonabilidad práctica que se impone en el debate sobre la organización social. A falta de criterios rigurosamente objetivos, en el último tercio del siglo XX la teoría política acabó decantando un método inter-subjetivo de deliberación y toma de decisiones basado en el uso público de la razón. Es a lo que llegaron por

\footnotetext{
1 Fundación Carolina
} 
sendas afines Jürgen Habermans y John Rawls y lo que constituye el fundamento del "liberalismo político". En este paradigma el papel de las emociones quedaba relegado por su irrelevancia metodológica, cuando no por su peligrosidad cívica.

Ciertamente, la sensación de miedo sirvió para que los contractualistas - netamente Hobbes - se figurasen de forma verosímil un estado de naturaleza anárquico y amenazante, pero solo para activar una concatenación de razonamientos dirigida al frío diseño del Estado. Tal anarquía, por lo demás, estaba íntimamente ligada con una concepción pesimista de la naturaleza humana, desde la que los founding fathers articularon el gobierno de las leyes, por encima del de los hombres. Igualmente, los utilitaristas o Rousseau apelaron, respectivamente, a los afectos primigenios del placer y de la bondad, mas de nuevo con el propósito de pensar un mundo ordenado a la perfección. De los primeros surgió la teoría de la elección racional y del ginebrino una noción proto-totalitaria de la política, que nos conminaba ("virtuosamente") a la libertad. Los cimientos del proyecto ilustrado, levantados sobre la creencia en la autonomía libre del sujeto individual, convenientemente instruida por la razón, permanecieron incólumes. La exaltación irracional de las pasiones en las "ideocracias" de entreguerras y los logros técnicos del positivismo científico contribuyeron a desterrar la toma en consideración de los sentimientos, los cuales sin embargo no cesaron de asomar, notablemente con ocasión del mayo del 68, penúltimo estertor del romanticismo idealista.

Cabe recordar que la clave epistemológica de esta corriente, germen del nacionalismo cultural, se nucleaba en torno a una tercera facultad cognoscitiva, introducida por Johannes N. Tetens, y emplazada entre el pensamiento, desde el que se accedería al orden natural, y la volición, orientada al orden moral. Se trataba de la facultad del sentimiento, instancia estética a partir de la cual según F. Schelling se podía sintetizar el conocimiento del mundo. Esta absorción de la realidad por la estética quedó no obstante confinada al terreno de las vanguardias y la especulación artística, pese a los episodios de estetización del poder totalitarios, los reincidentes ademanes nacionalistas o la citada revuelta francesa. Ahora bien, el reciente rebrote de movimientos populistas y chovinistas ha situado otra vez en primer plano la cuestión de la ascendencia de las pasiones en la política, al mismo tiempo que la neuro-ciencia está replanteando los presupuestos que explican la actividad fisiológica y cerebral humana, incorporando ahora un componente emocional. En este sentido, La democracia sentimental del profesor Manuel Arias Maldonado -que en adelante nos disponemos a comentar- es el libro oportuno publicado en el momento apropiado: una obra que cubre pormenorizadamente los progresos de la teoría política, actualizando y reubicando la disciplina a la altura de los tiempos, marcados precisamente por el "giro afectivo". 
Quizá no sea del todo inadecuado hablar de dos fenómenos deslindados. Los descubrimientos científicos no representan sino un capítulo más en el campo de la investigación empírica, que siempre ha privilegiado la experiencia sensible (los "datos de los sentidos"), mientras que la sentimentalidad que perfora a las democracias avanzadas apunta a una nueva vuelta de tuerca del romanticismo político?2.

Tal coincidencia permite no obstante enfatizar el impacto de dicho "giro" en las ciencias sociales e incidir en la erosión que está sufriendo del sujeto racional e ilustrado sobre el que estas se sustentaban. Bajo dicha óptica, el autor emprende un recorrido enfocado a preservar la tesis de la autonomía individual (a re-soberanizar al sujeto postsoberano) pero en virtud de nuevas bases, aquellas que proporciona el conocimiento cierto sobre los límites de nuestra racionalidad, vale decir: de nuestra naturaleza. De este modo, el texto camina haciendo equilibrios entre un movimiento pendular que empuja a las ciencias humanas, bien hacia el flamante "cerebro-centrismo" (M. Pérez Álvarez), bien hacia el determinismo lingüístico (el "il n'y a pas de horstexte" de J. Derrida) en el que en parte siguen encalladas. Una oscilación emparejada con la controversia sobre la influencia de la naturaleza y la cultura en la conducta humana y cuya resolución concierne de lleno al porvenir de la filosofía política - en rigor, al de la fundamentación de la convivencia social.

Atendiéndonos al "orden del discurso" examinaremos las propuestas de Arias Maldonado en el tramo final de la reseña. Previamente veamos cómo afronta el tratamiento de los afectos ${ }^{3}$, analizando en primer lugar los principios neurofisiológicos que nos obligan a reconsiderar las relaciones de fondo entre razón y emoción. Y ello por cuanto la evidencia empírica implica superar su estricta disociación, postulando en cambio una interacción que por de pronto ya se produce a nivel cerebral. Es preciso en este punto confirmar la existencia de cinco emociones primarias -alegría, angustia, as $\mathrm{CO}$, ira y miedo-, innatas o impresas en la neuro-anatomía humana (A. Damasio). Asimismo, este innatismo debe entenderse en la clave darwiniana de la psicología evolucionista, como fruto del proceso adaptativo de la especie; de ahí la funcionalidad racional de las emociones. Y, por último, hay que distinguir entre los afectos pre-conscientes y aquellas emociones y sentimientos conscientes, que experimentan un desarrollo cognitivo en función del contexto social. Aquí es cuando cobran relevancia los filtros perceptivos que enmarcan la comprensión conceptual, básicamente

\footnotetext{
2 Aunque tampoco puede olvidarse la influencia del empirismo inglés sobre Tetens. Esta misma ruta intermedia se adivina en la filosofía de G. Deleuze: inspirado por el empirismo de Hume y el vitalismo de Bergson, Deleuze subraya la supuesta reserva liberadora del ámbito sensorial, pre-consciente, previa a la fijación de la realidad por parte del lenguaje.

${ }^{3}$ En lo sucesivo, los conceptos de afecto, sentimiento y emoción se emplearán como si fueran sinónimos, tal y como hace con frecuencia el autor.
} 
de tipo lingüístico y que gracias a las técnicas del storytelling pueden condicionar, ahora en sentido inverso, nuestra disposición anímica. Y nuestras decisiones, hasta el grado de que lo que a menudo tomamos como juicios racionales están limitados por desviaciones en las que como se nos explica en el capítulo referido al "paternalismo libertario"incurrimos de manera inconsciente: impulsividad, presentismo, tendencia a la predicción optimista o a la norma prefijada, mimetismo, etc. En consecuencia, la interacción racional-emotiva presupuesta no solventa el dilema naturaleza/cultura (ni el autor lo pretende) dejándose la partida en tablas4.

Sirva como muestra la alusión a programas científicos que apelan a una moralidad innata, depurados por la selección natural, pero que aparecen igualmente rebatidos por hipótesis que dictaminan la "insignificancia normativa" de la neurociencia. En su lugar, de lo que se trata es de poner coto a las ambiciones reduccionistas, sugiriendo fórmulas que, ciertamente, han encontrado más repudio del lado de las ciencias humanas, supeditadas al paradigma del constructivismo social. En efecto, el "pensamiento crítico" no avanza rehuyendo el signo de los hallazgos científicos, de modo que las reacciones sociologistas ante el "efecto bikini" (p. 313) resultan ineficaces. De lo que se sigue que la neurociencia, aun sin fuerza normativa, sería capaz según Arias Maldonado de marcar en negativo delimitaciones naturalistas, desactivando el establecimiento de prescripciones sin fundamento: solo tomando conciencia de las disposiciones de nuestra naturaleza se pueden amortiguar 0 neutralizar normativamente sus efectos indeseables ${ }^{5}$. Y así, sobre la apoyatura de estas apreciaciones, cabrá salvaguardar una noción actualizada de la autonomía individual. Pero no conviene adelantarse; de momento la "querella disciplinar" entre materias exactas y blandas no repercute sobre el meollo del asunto: el del desgaste de sujeto ilustrado aplicado ya sobre el terreno de la política.

Es de hotar que el tema haya afectado a la metodología más robusta o "positiva" de las ciencias sociales: la de la elección racionalb. Sus premisas, modeladas por la escuela neoclásica de acuerdo con las preferencias lógicas de homo oeconomicus, se han visto sacudidas por la pujanza de una perspectiva sensitivo-conductual que introduce el juego de expectativas emocionales en la decisión final, mediadas con

\footnotetext{
4 En torno a la espinosa definición de la naturaleza humana, Arias Maldonado se limita a hablar, y seguramente con esto baste, de seres psico-biológicos condicionados por disímiles culturas socio-morales, en donde el aprendizaje por imitación constituye un factor evolutivo decisivo (pp. 104-ss.).

5 Más que retornar a la "falacia naturalista" se trataría de detener la resonancia de la "falacia moralista" (Bernard Davis).

${ }^{6}$ Muy convenientemente, su aplicador en la politología, James M. Buchanan, hablaba de: "Política sin romanticismo".
} 
asiduidad socialmente. Nos tropezamos de nuevo con el "giro afectivo", en principio estrictamente psico-neuronal, pero que se desliza hacia su versión más romántica cuando se abre el foco al mundo del consumo capitalista (Colin Campbell), dominado como bien saben publicistas y modistos por la ley del deseo. Que esto suceda en el ámbito en el que se suponía que las pasiones se habían traducido en forma de intereses (Albert $O$. Hirschman) es indiciario de la deriva con la que nos vamos a topar en la esfera política.

Téngase en cuenta que bajo la impecable fachada de neutralidad axiológica que blande la doctrina liberal, acecha una historia conceptual de fuerte impronta teológica que troquela sentimentalmente, como viera E. Voegelin, el contenido de las ideas políticas. La propia noción de ideología, entendida al modo marxista, configura "paquetes de creencias" de alto voltaje emocional, que ni siquiera resultan extirpables en la pulida interpretación de Michael Freeden: aun como sistemas de conceptos "decontestados" o cerrados semánticamente, las ideologías no dejan de generar tribus y culturas de adhesión -religiones secularizadas para tiempos desencantados. Desde este patrón se hace inteligible la eclosión romántico-política que terminó adquiriendo formato totalitario, tanto más seductora por las impenetrables esperanzas de futuro que sugería la revolución. Merece la pena reproducir la aguda cita a Raymond Aron que trae a colación Arias Maldonado: "El espíritu revolucionario se nutre de la ignorancia del porvenir. Marx tuvo mucho cuidado en no describir, ni esbozar siquiera, la sociedad socialista". La disposición ideológica del nacionalismo, de suyo excluyente, adopta una función análoga, si es que detectamos sus orígenes en el momento en el que Estado e Iglesia quedan segregados y la soberanía encuentra su legitimidad en el cuerpo de la nación. El apego sentimental, tenga o no aval histórico (cuestión no menor, pero fútil a nuestros efectos), debió apuntalarse a base de símbolos y relatos, acudiendo a partir del siglo XIX a los mecanismos públicos consabidos: educación, milicia y, en la posterior centuria, medios de comunicación, sobre los que enseguida volveremos. Es pertinente la precaución que esgrime el autor, de mano de Bernard Yack, ante el subterfugio que aplica un corte limpio e intransferible entre el nacionalismo políticocívico y el cultural: pese a la evidente contingencia de nuestro lugar de nacimiento, no es fácil erradicar por completo sus implicaciones emocionales, ni las huellas que acuña la socialización. Lo cual no es óbice para renunciar a las raíces, distanciarse de la pertenencia identitaria, ni que digamos para refutar la prevalencia jurídica de los derechos colectivos sobre los individuales. Tal línea de razonamiento cae no obstante del lado del apartado prescriptivo que el autor retomará en las conclusiones.

Persiguiendo el rastro de la política sentimental llegamos hasta nuestros días, en los que no es equivocado tildar a las democracias como 
regímenes de opinión pública. La hipótesis, en su exégesis más animosa, cuenta con el respaldo del aparato teórico de Habermas, para quien la esfera pública, como lugar de intercambio de ideas a la luz de la razón, propicia el soporte de legitimidad en los Estados de derecho. El problema estriba en que los medios de comunicación, y ante todo la televisión, lejos de haberse convertido en instancias racionales de referencia (aun pervertidas por la racionalidad instrumental del mercado), anteponen los contenidos sensacionalistas -en su doble sentido: sensitivo y espectacular-, restringiendo la experiencia ciudadana a la de espectadores pasivos. Esta tendencia es la que permite hablar de democracia de audiencia, videocracia 0 democracia ocular7, en la que el comportamiento de los candidatos prima sobre la coherencia de los partidos o su solidez programática. En todos los casos queda intensificada la dimensión sentimental. Por su parte, el aspecto interactivo de internet tampoco parece haber contribuido a restablecer la calidad del debate cívico. Las consideraciones más favorables, en torno a las virtudes del conocimiento compartido en Wikipedia 0 de las conversaciones persuasivas en las redes, se ven eclipsadas por la generación de un "pensamiento enjambre" (Byung-Chul Han) que opera por contagio, cuando no se abandona al linchamiento hostil (shitstorms). Con independencia del diagnóstico, Arias Maldonado registra la emergencia de una "fenomenología de la digitalidad", reflejada en la habituación de nuevas costumbres sensoriales que -y a eso íbamosafianzan el anclaje del "giro afectivo". La política desemboca por tanto en una batalla por captar percepciones y generar emociones; dicho de otro modo: por llamar la atención. He aquí quizá el síntoma más intuitivo de su carácter infantil. Ahora bien, una vez constatada la sensibilidad de la razón y la rentabilidad propagandística de los sentimientos, el buen criterio no aconseja obviar su connotación política, de modo que la tarea del autor pasa por incorporarlos al liberalismo democrático o, cuando menos, por contrarrestar la perniciosidad de su inevitable comparecencia.

Antes resulta ilustrativo pasar revista sobre las emociones que han acompañado, a veces desde el origen de la civilización al discurso y práctica de la política. A este respecto, la distinción planteada entre afectos positivos y negativos no contiene juicio de valor alguno, en la medida que, como se dice, "de buenos sentimientos está empedrado el suelo del infierno"8, veredicto del que no se deduce carta blanca para los malos humos. No es necesario explayarse sobre la temeridad que supone emplear el amor como estandarte político, a poco que cada cual indague en su propia experiencia e infiera el carácter ilógico de este sentimiento. Aunque nunca esté de más recurrir al magisterio de

\footnotetext{
7 Según hablemos de B. Manin, G. Sartori o J. Green.

$8 \mathrm{O}$, parafraseando a André Gide, con buenos sentimientos no se hace buena política.
} 
H. Arendt para recordar que el amor tan solo sobrevive en el ámbito privado (La condición humana). Algo semejante cabe afirmar sobre la intimidante bondad roussoniana de la que ya se ha hablado. La amistad, por el contrario, conserva su predicamento en el terreno politológico, debido a su emplazamiento preeminente en la obra aristotélica ("en cada una de las formas de gobierno la amistad aparece en la misma medida que la justicia"9) y, desde luego, en la categorización política de Carl Schmitt. El cambio de escala morfológica que han sufrido tos Estados desde los tiempos del estagirita - las consecuencias beligerantes que apareja el pensamiento del alemán atemperán el discernimiento de Arias Maldonado en relación a su potencial cívico o, como menciona al citar a Derrida, fraternal —más allá de la ley. La symphaty de la llustración escocesa guarda asimismo una alta reputación en la historia del pensamiento político ${ }^{10}$, seguramente porque su imbricación con el entendimiento (en tanto razonamiento "afectado") anticipa lo descubierto dos siglos después. De ahí el paralelismo entre la figura del "espectador imparcial" de Adam Smith y la actitud de imparcialidad como "sensibilidad reflexiva" que en nuestros días propugna Sharon Krause, pero que como explica el autor no ha logrado cuajar en un diseño institucional acabado. Un reproche similar al que se enfrenta la obra de M. Nusbaum, no fundamentada esta vez en un solo sentimiento. Su proyecto acomete la orquestación de un "liberalismo emocional" que incentiva la revitalización de un conjunto de buenos afectos, otorgando relevancia singular al patriotismo. Los planes de actuación simbólicos que receta (museístico, monumental...) descuidan no obstante, según indica Arias Maldonado, el alcance de la cultura popular.

Las cosas no cambian mucho al situarnos en el lado oscuro de las emociones, donde encontramos un repertorio todavía más amplio de las mismas, atravesando la historia política. En la actualidad, y entroncando con el miedo hobbesiano, Judith Shklar ha insistido -a diferencia de Nussbaum - en el sentimiento de misantropía como eje de la arquitectura democrático-liberal. Con todo, los arrebatos negativos se vinculan más bien con corrientes iliberales. Así se desprende del análisis que se hace de la ira, el resentimiento y la enemistad "agonística". Y es que, sin perjuicio de los equilibrios trazados por Rawls -formulando un principio de igualdad de oportunidades emparentado con el óptimo paretiano- en orden a impedir la aparición de la envidia (al menos justificadamente), la santa indignación puja por romper los engranajes institucionales. Pasado el tiempo en el que el resentimiento se interpretaba, precisamente, como afecto indigno (Nietzsche, Scheler), su manifestación ha pasado a

9 "De la amistad", Libros VIII y IX de la Ética a Nicómaco.

10 Como es sabido, los primeros teóricos del sentimiento moral son David Hume y Francis Hutcheson. Les precede Shaftesbury, para quien el sentimiento moral coincidía con el sentimiento estético. 
cobrar naturaleza de causa justa, a menudo al margen de su motivo. Ello, unido a la dificultad por precisar de manera cabal los factores explicativos del cambio socioeconómico en la globalización, ha conducido a una relectura de la realidad política en clave de conflicto, incluso de hostilidad, explícitamente sentimentales. En este caldo de cultivo ha germinado ese fenómeno inasible que lleva el nombre de populismo y cuya teorización más célebre ha corrido a cargo de E. Laclau y Ch. Mouffe.

Tal y como lo presenta Arias Maldonado la base del populismo es diametralmente opuesta a la del liberalismo, debido a que las sociedades no se articularían sobre bases racionales sino sentimentales. En este sentido, resulta capital entender el momento fundacional en torno al que gira, más allá de los rasgos de hiper-liderazgo o simplificación de la complejidad con los que se le caracteriza. En consecuencia, toda política sería populista en origen, dado que lo que entonces está en juego es la consolidación de una matriz hegemónica, deferminada por un sujeto político frente a otros. Esta lógica conflictiva - pues de eso se trata al cabo, no de una ideología ni de un movimiento, sino de una lógica no consensual de acción políticaenfrenta en última instancia al pueblo contra las élites. Su novedad radica en que reintroduce el conflicto en el seno de la democracialiberal, con el fin de refundar el sistema establecido, y superarlo. Dejando de lado la carga existencial ("schmittiana") comprometida en esta concepción, o los mecanismos discursivos que integra cohesionando demandas dispersas-, el populismo se distingue, pues, por invocar la guerra sin declararla, removiendo todos sus recursos simbólicos de animadversión, pasionales justamente, evitando tomar las armas ${ }^{11}$. El radar de amplio espectro en el que se desenvuelve el autor le permite reconocer en las investigaciones de George Marcus un sostén neuronal al asunto: la estimulación de la ansiedad es susceptible de perturbar nuestras "rutinas cognitivas" y abrirnos a planteamientos inéditos. No es verosímil sin embargo imaginar un estado de movilización y activismo perpetuo, menos aún una arquitectura institucional que lo estabilice. Un problema de institucionalización que se extiende a la lógica populista, salvo que termine encauzada en el entramado social del liberalismo. De hecho, es lo que insinúa Arias Maldonado, al subrayar que este modelo incorpora más conflicto o convoca menos consenso que lo que el populista presume.

\footnotetext{
11 Sorprende en los análisis del ámbito anglo e hispano-hablante la poca atención que depara el contrincante natural de Ch. Mouffe, A. de Benoist (salvando excepciones: R. Griffin, M. A. Simón, J. Verstrynge, etc.). Teórico del populismo de la Nueva Derecha francesa e inspirador original del ideario del Frente Nacional, Benoist lleva décadas reivindicando el concepto de hegemonía gramsciana, aparte del magisterio de C. Schmitt, y defendiendo la instauración de una democracia participativa, antiliberal, pagana, ecologista incluso, de fuertes liderazgos y respetuosa hacia la diversidad cultural (sin mezclas, eso sí).
} 
Llegados a este punto, su último objetivo consiste en perfilar una propuesta normativa que renueve el atractivo del liberalismo político o que, como mínimo, ejerza resistencia acreditada ante el embate emocional. Ya se nos han suministrado algunas pistas, toda vez que las pesquisas de Nussbaum, Krause o Shklar encuentran cabida dentro del mapa conceptual rawlsiano, por no abundar en los matices sentimentales que engloba el legado liberal o maneja el propio Rawls al abordar la envidia. A su vez, el autor se posiciona moderadamente a favor de los nudges del "paternalismo libertario" (pese al nombre, de corte socialdemócrata) que nos "empujan" a tomar decisiones que corrigen nuestros sesgos racionales. No se trata tanto de la "obligación a ser libres", como de invitar a una elección más informada, justificando tan solo el intervencionismo para eludir el daño a terceros, en sintonía con la tradición liberal-progresista de John Stuart Mill. Pero la intención de Arias Maldonado da un paso más y procura poner al día el ideal democrático ilustrado, dando relativo acomodo al "giro afectivo". En realidad, la adecuación del liberalismo a los avances de la neurociencia no revisten mayor trastorno, en función de la autonomía reforzada - aun en apariencia debilitada- que a fin de cuentas suscita conocernos mejor. No obstante, de ello se sigue un alegato del liberalismo en tono menor, cómplice de la visión irónica y postmetafísica de Richard Rorty. El razonamiento parte de un pluralismo axiológico que decreta la contingencia de los valores que articulan el poso creencial de las sociedades. La tentación nihilista se vence gracias a una definición de la democracia liberal en términos de meta-valor, como único régimen capaz de gestionar la coexistencia de distintas cosmovisiones. De alguna forma, el liberalismo vertería al lenguaje político la naturaleza de tal pluralismo, recibiendo así el atributo decisivo que le faculta para ser calificado de sistema abierto ("sociedad abierta"12). Pero esta interpretación del liberalismo político no ha impedido que sus críticos continúen delatando la persistencia de valores densos en el trasfondo de su simulación escéptica (M. Walzer). Resulta por lo demás llamativo que Arias Maldonado recurra a un autor indiferente a los adelantos neuro-políticos -en última instancia, un relativista epistemológico- cuya polémica con Steven Pinker fue

12 Con el permiso de E. Voegelin, quien en los años cincuenta, en una carta a Leo Strauss, afirmaba: "Este Popper ha sido durante años no exactamente una piedra con la que uno se tropieza, sino una china molesta que tengo continuamente que apartar del camino porque constantemente la gente me mienta su trabajo sobre 'la sociedad abierta y sus enemigos' como una de las obras maestras de nuestro tiempo (...). Lo menos que se puede decir es que es un libro impúdico, mierda diletante. Cada frase es un escándalo. (...) Las expresiones 'sociedad cerrada' y 'sociedad abierta' están tomadas de las Deux Sources de Bergson sin explicar las dificultades que indujeron a Bergson a crear esos conceptos (...). Si la teoría de Bergson sobre la sociedad abierta es histórica y filosóficamente consistente (que es lo que creo), entonces la idea de la sociedad abierta de Popper es basura ideológica". 
célebre (no lo es tanto cuando acude a M. Oakeshott, siquiera sea por su talante escéptico-conservador) ${ }^{13}$. Por fin, la inteligente apelación a la melancolía, apta para los espíritus ponderados, se antoja un remedio evanescente ante la intermitente violencia de los asaltos románticos.

Estas reflexiones no merman la magnitud de una obra excepcional, repleta de hallazgos y que invita a profundizar en múltiples líneas de investigación, alguna de las cuales - por cierto- enlazan con estudios lanzados desde España. Así, cuando se hace referencia al papel del desacuerdo en la configuración de la idea-de justicia (Gerald Gaus), cabe pensar en la "alternativa del disenso" que teorizó J. Muguerza como criterio de legitimidad democrática. Las menciones a la "deliberación retórica" y la "deliberación interior" evocan la recuperación de los rétores y la reivindicación del espacio público interno en la obra de J. Roiz. El interrogante que se pregunta cómo se propagan socialmente las emociones podría rescatar el concepto de "epidemiologia de las representaciones", del antropólogo Dan Sperber, que también ha utilizado el sociólogo E. Gil Calvo. Por fin, en esta misma estela mimética, acaso no sería desatinado recolocar el alcance del "giro afectivo" en el mismo perímetro académico del "giro pragmático", ubicado en las lindes de un giro lingüístico más analítico que postmoderno -es lo que en parte viene proponiendo J. Gomá. En todo caso, este libro trae buenas noticias para los teórico-políticos: quedan infinidad de mundos por explorar.

13 Como explica John Gray: "En el pasado, la derecha representaba una aceptación realista de la flaqueza humana y la consiguiente visión escéptica sobre la posibilidad del progreso. No se oponía por sistema al cambio, pero rechazaba rotundamente cualquier concepción de la historia entendida como una marcha triunfal hacia cumbres iluminadas por el sol. La política era vista como una manera de afrontar la imperfección humana. A menudo, esta visión de las cosas se fundamentaba sobre la doctrina cristiana del pecado original, pero también se puede encontrar una variante de esa misma idea entre pensadores conservadores no abonados a tales creencias. Religiosa o no, lo cierto es que la derecha entendía que era imposible superar los defectos de la naturaleza humana", en Misa Negra, Barcelona: Paidós, 2008, p. 51. 


\section{Referencias bibliográficas}

Arendt, H. (201 1): La condición humana, Paidós, Barcelona.

Arias Maldonado, M. (2016): La democracia sentimental, Página Indómita, Barcelona.

Buchanan, J. M. (1979): "Politics without romance: A sketch of positive public choice theory and its normative implications", Inaugural lecture, Institute for Advanced Studies, Viena.

Damasio, A. (1994): Descartes' Error: Emotion, Reason and the Human Brain, Avon, Nueva York.

Davis, B. D. (1978): "The moralistic fallacy", Nature, 272, 390.

Deleuze, G. (1988): Diferencia y repetición, Júcar, Madrid.

Gil Calvo, E. (2004): El miedo es el mensaje. Riesgo, incertidumbre y medios de comunicación, Alianza Editorial, Madrid, 2004.

Gray, J. (2008): Misa Negra, Paidós, Barcelona.

Muguerza, J. (1989): "La alternativa del disenso", en El fundamento de los derechos humanos, Debate, Madrid.

Pendás, B. (2007): Teorías políticas para el siglo XXI, Síntesis, Madrid.

Pérez Álvarez, M. (2011): El mito del cerebro creador: cuerpo, conducta y cultura, Alianza, Madrid.

Pinker, S. (2003): La tabla rasa: la negación moderna de la naturaleza humana, Paidós, Barcelona.

Roiz, J. (2003): La Recuperación del Buen Juicio. Teoría política en el siglo veinte, Ed. Foro Interno, Madrid.

Rorty, R. (2008): "Philosophy-Envy", Daedalus, vol. 133, No. 4, "On Human Nature" (otoño 2004).

Simón, M. A. (2007): La extrema derecha en Europa desde 1945 a nuestros días, Tecnos, Madrid.

Sperber, Dan (1985): "Anthropology and psychology: towards an epidemiology of representations", The Malinowski Memorial Lecture, 1984, Man (N.S.) 20.

Walzer, M. (1996): Moralidad en el ámbito locale internacional, Alianza, Madrid. 